\title{
CONTRATOS DE COMUNICAÇÃO E ANÁLISE DO DISCURSO: BASES TEÓRICAS APLICADAS AO ENUNCIADO PERSUASIVO DE MODA MASCULINA.
}

\section{Contracts for communication and discourse analysis: theoretical applied to persuasive statement of menswear.}

\section{Los contratos de comunicación y el análisis del discurso: teórica aplicada a la declaración persuasiva de ropa de hombre}

Allan Kozlakowski ${ }^{1}$

\section{Resumo}

O artigo apresenta parte dos estudos conceituais aplicados à análise do discurso, caracterizando os fundamentos da pesquisa sobre o discurso do empreendedor de sucesso, veiculado nas revistas de negócios Você S/A e Exame, ambas publicações brasileiras. Tais revistas prometem orientação para jovens executivos e 'futuros homens de negócios', com receitas para o sucesso, incluindo roteiros para alcançar o ápice profissional, conforme as condições de consumo contemporâneas. Objetiva-se com o recorte apresentar as bases conceituais para a análise do discurso persuasivo dos anúncios de moda masculina executiva, presentes nas publicações destacadas e em outras diversas, dos veículos semanais informativos aos dedicados ao entretenimento. As perspectivas teóricas aproximarão a análise da mensagem publicitária ao conceito de contrato de comunicação de Patrick Charaudeau pela relação entre o quadro de referência presumido entre os interlocutores no contrato de comunicação e o desenvolvimento de hábitos - proposta por Peirce - que levam à fixação das crenças. Tal desenvolvimento observará a operação do signo indexical, na análise da mensagem publicitária, abordado por Santaella. Partindo desta aproximação conceitual, o artigo discutirá a abordagem sobre um dos motivos que podem gerenciar a eficácia contratual dos anúncios, conforme o conceito de substância

\footnotetext{
${ }^{1}$ Doutorando pelo Programa de Estudos Pós-graduados em Comunicação e Semiótica da Pontifícia Universidade Católica de São Paulo, Brasil. allankws@ hotmail.com
} 
Contratos de comunicação e análise do discurso: bases teóricas aplicadas ao enunciado persuasivo de moda masculina

de Allan Koslakowski

cultural proposto por Baudrillard, e segundo a lógica dos produtos culturais na busca da performance adequada, tanto na vida particular quanto na atuação profissional. Conforme a construção de regimes de visibilidade e interação, proposta por Prado, o artigo focará as relações entre produtos e pessoas nas tematizações orientadas pelos contratos de comunicação, e referir-se-ão à busca pelo consumo de produtos que traduzem o homem de sucesso. Desta forma, o trabalho investigará possibilidades de desconstrução e reconstrução da sensação de conflito entre o 'ser eu' e 'ser alguém', organizado por João Freire Filho, como resultado da mensagem publicitária da marca ARAMIS, “mens wear”. Assim, espera-se que o ensaio conceitual colabore para agrupar conceitos necessários visando compreender o valor semiótico agregado por meio da transferência de características do vestuário masculino para atingir os sentimentos pessoais e organizar a construção do 'ser alguém'; desta forma, esperamos poder demonstrar a configuração do culturalmente aceito como destaque do 'ser consumidor' pela exaltação ao pertencimento a determinado grupo de pessoas. Tais estudos indicam em sua trajetória final a eficácia do discurso publicitário, explicitando algumas relações socioculturais que atuariam no processo de construção dos discursos, especialmente os destinados às experiências da felicidade, fundamentalmente pela análise dos signos do anúncio.

Palavras-chave: contrato de comunicação, análise do discurso, persuasão, publicidade.

\begin{abstract}
The article presents some conceptual studies applied to the analysis of discourse, characterizing the fundamentals of research on the discourse of successful entrepreneur, business magazines Você SA and Exame, both Brazilian publications. Such magazines promise and guidance for young executives 'future businessmen', with recipes for success, including roadmaps to achieve professional apex as the conditions of contemporary consumption. It aims to cut the present the conceptual basis for the discourse analysis of persuasive advertisements menswear executive, present in prominent publications and other miscellaneous vehicles weekly newsletter dedicated to entertainment. The theoretical perspectives will approach the analysis of advertising to the concept of contract reporting by Patrick Charaudeau relationship between the reference frame assumed in the contract between the interlocutors of communication and the development of habits - proposed by
\end{abstract}


Contratos de comunicação e análise do discurso: bases teóricas aplicadas ao enunciado persuasivo de moda masculina

Peirce - that lead to the fixation of belief. Such development will observe the operation of the indexical sign, analysis of the advertising message, addressed by Santaella. Building on this conceptual approach, the article will discuss the approach on one of the reasons that can manage the effectiveness of contract announcements, as the concept of cultural substance proposed by Baudrillard, and according to the logic of cultural products in the search for adequate performance, both in private life and in professional practice. As building visibility and interaction schemes, proposed by Prado, the article will focus on the relationship between people and products in thematizations guided by contracts for communication, and will refer to the search for the consumption of products that translate the successful man. Thus, the work will investigate possibilities of deconstruction and reconstruction of conflict between the feeling of 'being me' and 'be somebody', organized by John Freire Filho, as a result of the advertising message of the brand ARAMIS, "mens wear". Thus, it is expected that the test conceptual collaborate to group concepts needed to understand the possible semiotic value added through the transfer characteristics of menswear to achieve personal feelings and organize the construction of 'be someone', this way, we hope to demonstrate configuration culturally accepted as highlight of 'consumer be' the exaltation of belonging to a particular group of people. Such studies indicate in its final trajectory the effectiveness of advertising discourse, explaining some sociocultural relationships that act in the construction of discourses, especially those destined experiences of happiness, mainly by analyzing the signs of the ad.

Keywords: contract of communication, discourse analysis, persuasion, advertising.

\section{Resumen}

El artículo presenta algunos estudios conceptuales aplicados al análisis del discurso, la caracterización de los fundamentos de la investigación sobre el discurso del empresario exitoso, en revistas de negocios Você S / A y Examen, ambas publicaciones brasileñas. Las revistas prometen orientación para futuros "empresarios" ejecutivos jóvenes, con recetas para el éxito, incluyendo hojas de ruta para lograr el tope profesional, como previsto en las condiciones de consumo contemporánea. Su objetivo es servir de base conceptual para el análisis del discurso persuasivo ejecutivo de la publicidad de ropa masculina, presente en importantes publicaciones y otros vehículos dedicados al entretenimiento. Las perspectivas 
Contratos de comunicação e análise do discurso: bases teóricas aplicadas ao enunciado persuasivo de moda masculina

de Allan Koslakowski

teóricas abordarán el análisis de la publicidad al concepto de presentación de informes contrato por Patrick Charaudeau relación entre el marco de referencia adoptado en el contrato entre los interlocutores de la comunicación y el desarrollo de hábitos - propuesto por Peirce - que conducen a la fijación de creencias. Este desarrollo se observa el funcionamiento de la signo indicial, el análisis del mensaje publicitario, dirigida por Santaella. Sobre la base de este enfoque conceptual, el artículo discutirá el enfoque sobre una de las razones que pueden administrar la eficacia de los anuncios de contratos, como el concepto de sustancia cultural propuesta por Baudrillard, y de acuerdo a la lógica de los productos culturales en la búsqueda de un rendimiento adecuado, tanto en la vida privada y en la práctica profesional. Como la construcción de sistemas de visibilidad e interacción, propuesta por Prado, el artículo se centrará en la relación entre las personas y los productos en tematizaciones guiados por los contratos de la comunicación, y se referirá a la búsqueda del consumo de productos que traducir el hombre de éxito. Por lo tanto, el trabajo será investigar las posibilidades de la deconstrucción y la reconstrucción del conflicto entre el sentimiento de "ser yo" y "ser alguien", organizado por Juan Freire Filho, como resultado del mensaje publicitario de las marcas ARAMIS, "mens desgaste". Por lo tanto, se espera que las pruebas puedan colaborar a agrupar conceptos necesarios para entender el posible valor semiótico añadido a través de las características de transferencia de ropa de hombre para lograr sus sentimientos personales y organizar la construcción de "ser alguien", de esta manera, esperamos poder demostrar configuración culturalmente aceptado como punto culminante de «consumidor ser" la exaltación de la pertenencia a un determinado grupo de personas. Estos estudios indican en su trayectoria final de la eficacia del discurso publicitario, explicando algunas de las relaciones socioculturales que actúan en la construcción de los discursos, especialmente los destinados experiencias de felicidad, principalmente mediante el análisis de los signos del anuncio. Palabras-clave: contrato de comunicación, análisis del discurso, persuasión, publicidad.

\section{QUADRO DE REFERÊNCIA PARA A PERSUASÃO E A FIXAÇÃO DA CRENÇA: INTERFACES TEÓRICAS}


Contratos de comunicação e análise do discurso: bases teóricas aplicadas ao enunciado persuasivo de moda masculina

de Allan Koslakowski

Os acordos existentes entre os consumidores da informação e os respectivos veículos de comunicação que as disseminam são definidos no ato de consumo e se realizam a partir de um contrato de comunicação. A ideia de um contrato de comunicação pode ser considerada uma das questões centrais dos estudos de Patrick Charaudeau sobre os discursos produzidos pelas mídias. Ele conceitua a existência de uma espécie de pacto entre enunciador e enunciatário na relação de consumo dos produtos dos veículos de comunicação. Os contratos de comunicação estabelecem associações entre a materialidade simbólica e o leitor e, segundo Charaudeau, apresenta "algumas condições particularizadas e restrições" (2006: 68) que regulam as expectativas de troca entre o enunciador e o enunciatário. Essas condições mínimas são observadas pelo autor como constituintes dos quadros de referência pela recorrência de determinadas modalidades discursivas para delinear a coerência necessária à troca.

O quadro de referência proposto por Charaudeau (2007) preconiza a existência de uma organização de sentidos para gerar a enunciação realizadora do pacto entre enunciador e enunciatário e tal organização seria parte do sistema desenvolvido pelas sociedades contemporâneas - principalmente as ocidentais - para manter-se a importância e predomínio da sociedade da informação e comunicação (Rüdiger, 2011). Pode-se depreender que tal predomínio é dado pelo consumo da informação e que sem esta organização não haveria condições de instauração da interlocução e da atualização necessária para se processar o sentido da comunicação. Enquanto condição mínima, o quadro pressupõe o reconhecimento de referências comuns pelos participantes; assim, as informações são negociadas na troca comunicacional.

A partir do reconhecimento dos papéis (enunciador e enunciatário), as expectativas sobre o que esperar são projetadas pelo veículo de comunicação num leitor idealizado, da mesma forma que o enunciador é reconhecido pelo posicionamento político de sua enunciação e não pela autoria. Pode-se dizer que um conjunto de referências comuns é utilizado para cada contrato e que tais referências elucidam as identidades projetadas, as finalidades e as restrições do pacto (contrato). Segundo Rüdiger (2011: 39), "... a sociedade se confunde em sua estrutura com a cultura, na medida em que representa um fenômeno gerado simbolicamente pela comunicação." e, dessa forma, o processo de consumo se realiza e atualiza. 
Contratos de comunicação e análise do discurso: bases teóricas aplicadas ao enunciado persuasivo de moda masculina

Importante ressaltar que os contratos não são inteiramente apresentados num texto midiático, mas expostos em coerência articulada pelo veículo de comunicação em suas estratégias sobre o enunciatário. Os contratos, dessa forma, precisam reconhecer as dinâmicas do contexto sociocultural desse enunciatário e, por isso, necessitam dos quadros de referência para estabelecer "os lugares de enunciação" (Maingueneau, 1996: 10). A natureza dos contratos, portanto, presume interface entre os produtores e os receptores da comunicação em sua operação enunciativa, em atividade intersubjetiva na aceitação ou negação do pacto que os relaciona no próprio sistema. Para tanto, como veremos, há necessidade de organizar os temas para que haja a compreensão da situação que auto alimentará todo o sistema.

"Sob a batuta da dupla finalidade de credibilidade e captação, as restrições relativas à posição das instâncias de comunicação e à captura do acontecimento dão instruções e impõem um modo de organização do discurso em um ordenamento temático." (Charaudeau, 2007: 129)

Dessa forma, podemos elaborar uma síntese sobre a operação do contrato comunicacional das mídias: primeiro, infere um leitor ao organizar temas e discursos voltados a ele, com finalidade estratégica e visando caracterizar seu pacto relacional e, segundo, não dispõe de espaços efetivos para a troca entre as instâncias de produção e de recepção, pois a interatividade entre estes é simulada pelo ato de consumo. O princípio da troca, dessa forma, estabelece:

“... um saber e uma competência: um pedido para dizer que pressupõe um poder de dizer do segundo e que, ao mesmo tempo, provoca um dizer desse último. Sendo assim, estabelece-se uma relação de solicitante e solicitado cujo vínculo depende da situação de troca." (Charaudeau, 2007: 50)

Sem esta configuração relacional o sentido de contrato (de condução das responsabilidades pela enunciação) não existiria, pois a essência do acordo é a presunção ao consumo. Pode-se afirmar, então, que o enunciatário poderia optar por outro quadro de referências mais afeito às suas expectativas caso o posicionamento do enunciador não mais o subsidiasse em suas necessidades, levando-o a interromper o pacto. Aqui há o estabelecimento da razoabilidade do contrato (Charaudeau, 2007), pois as opções são as de projeção (por parte do enunciador) e as de inserção (por parte do enunciatário), condições 
Contratos de comunicação e análise do discurso: bases teóricas aplicadas ao enunciado persuasivo de moda masculina

de Allan Koslakowski

essas de intersubjetividade (composta) que estabilizam o quadro de referências pela necessidade de atualização, próprias ao sistema de comunicação.

As preferências de um e de outro dos envolvidos no contrato é situação complexa, pois a existência do pacto é gerada pela atitude. Podemos propor um raciocínio: a noção do enunciatário sobre sua participação é restrita ao ato econômico de consumo pela aceitação do ordenamento temático e sem a percepção do valor de troca sociológico (Baudrillard, 2010). Da mesma forma, a "instância midiática é feita de múltiplos atores, o que não permite distinguir o responsável pelo ato de comunicação" (Charaudeau, 2007: 242). Assim, o quadro de referência é regulador do processo de comunicação, pois faz circular um objeto de saber (os assuntos tematizados) por suposição estratégica do enunciador na construção de efeitos visados e subsidiados pela comunicação social.

\begin{abstract}
"Os sujeitos sociais não chegam senão de maneira indireta ao entendimento, através de uma certa objetividade, que não é apenas deles (e que não é só a linguagem, enquanto sistema de signos). A interação social necessariamente põe em jogo um terceiro simbolizante, a exterioridade de um polo neutro, que, ocupando uma posição de referência possível tanto para um quanto para outro, sem ser só para um, reúne-os com suas diferenças." (Queré, 1982: 32-33, in Rudiger, 2011: 101)
\end{abstract}

De certa forma, o enunciatário do contrato comanda a continuidade do acordo. $\mathrm{O}$ agendamento temático e o discurso performativo dos veículos de comunicação visam efeitos de verdade e esta é definida culturalmente, especialmente em áreas demandadas pelo sistema de produção de sentidos. Segundo Charaudeau (2007), verdade e crença estão ligadas ao imaginário de cada grupo social; dessa forma, podemos inserir nos estudos sobre as condições de sucesso de um contrato a convergência entre o quadro de referência e a crença. Definida na lógica peirciana como “... a natureza de um hábito...” e “... algo tal como a verdade, verdade que se distingue da falsidade simplesmente porque sua ação nos leva ao ponto que desejamos atingir..." (Peirce, 2008: 58), a crença é pressuposto ao pacto do contrato de comunicação.

Ao crer no texto publicado e no discurso do veículo, o enunciatário declara sua aptidão (portanto concordância) em consumir aquilo que a capa expõe: agir em razão dos temas propostos. Mesmo sabendo não se tratar de ato imediato, posterior e instantâneo, essa ação na direção da aceitação da troca que o enunciado do veículo propõe é a primeira 'concordância' do contrato em ato e, portanto, hábito que regra a conduta do enunciatário. A 
Contratos de comunicação e análise do discurso: bases teóricas aplicadas ao enunciado persuasivo de moda masculina

de Allan Koslakowski

eficiência do contrato pode ser verificada pela aquisição do hábito em sociedade, pois a partir dele pode-se admitir a fixação da crença pelos saberes tematizados no veículo de comunicação. Esses corroboram situações consideradas importantes e afirmam, com maior ou menor intensidade, que há, segundo Peirce (2008), performance de autoridade nas estratégias do enunciador.

"O espaço de tematização é onde é tratado ou organizado o domínio (ou domínios) do saber, o tema (ou temas) da troca, sejam eles predeterminados por instruções contidas nas restrições comunicacionais ou introduzidos pelos participantes da troca." (Charaudeau, 2007: 71)

Dessa forma, podemos afirmar que a continuidade da publicação é resultado da aquisição de hábitos pré-estabelecidos socialmente e do uso do sistema comercial, pela troca de valor econômico. O funcionamento ajustado do espaço de tematização é o que dá vazão às identificações essenciais ao contrato e mantém a convicção e a valorização pelo quadro de referência. Reforça-se, desta forma, que o contrato de comunicação se efetiva pelo preenchimento de uma determinada lógica social, cultural e econômica, relacionado aos hábitos.

Segundo Peirce (2008), a materialização da lógica da natureza nas ações humanas é dada pelo confronto com o outro, um segundo, e sua resolução, a comunicação (terceiridade), visando justamente a necessidade de se expor para este outro. A conduta resultante desta lógica é, essencialmente, a necessidade de representação (terceiridade). Alguns destes hábitos podem ser assinalados em nosso estudo como princípios do sistema de enunciação do contrato de comunicação e, dessa forma, regulam sua complexidade interna. O sucesso do contrato de comunicação está condicionado ao modo como as informações tematizadas convergem à crença que o sistema gera. Em oposição ao sucesso performativo dos temas, podemos admitir que o contrato possa vir a ser 'rompido' quando não provocar o raciocínio habitual. Quando o discurso do veículo não causar mais a corresponsabilidade no enunciatário o contrato tende a se extinguir, pois deixou a eficiência social (não 'se cumpriu' o contrato).

A credibilidade atribuída ao veículo de comunicação pelo enunciatário resulta do sistema de interação mediada simbolicamente (Rüdiger, 2011: 98) e ocorre, segundo Charaudeau, pela suposição de “... que a informação que lhe é proposta será direta ou 
Contratos de comunicação e análise do discurso: bases teóricas aplicadas ao enunciado persuasivo de moda masculina

de Allan Koslakowski

indiretamente útil para orientar sua conduta." e "... principalmente para poder ocupar certa posição social, estabelecer relações com o outro...” (2007: 80). Segundo Peirce (2008: 56), isso ocorre porque "O método da autoridade sempre governará a massa da humanidade;" e a continuidade de tal conduta social materializar-se-á sempre como um sentimento de que 'sempre há algo a alcançar', determinado pelas condições da lógica social. Assim, podemos acrescentar alguma observação sobre os contratos de comunicação pela emergência dos discursos pós-modernos que indicam a necessidade de alcançar a felicidade a partir de modelos prontos.

\section{CONTRATOS DO SUCESSO: A CRENÇA NA FELICIDADE}

Os contratos de comunicação evidenciam posicionamentos socioculturais e correspondem à conjunção de enunciados visando determinado perfil de público. Os moldes de tratamento da informação para tal conjunção, segundo Charaudeau (2008), constituem apenas uma parte do discurso informativo, pois existem espaços estratégicos para uma co-construção permanente de sentidos dada a influência externa à própria publicação e que deve representar o consumido pela parcela social descrita no perfil. Partindo da ideia de que existam tais espaços, a contribuição atual das instâncias midiáticas, face à "racionalização comunicativa do mundo da vida." (Rüdiger, 2011: 107), providenciam a construção de individualidades que, segundo Prado (2008), impõe determinados significantes de sucesso, como os padrões estéticos e orientações para o gozo. Baudrillard afirma:

\footnotetext{
"Em última análise, o que acontece aos indivíduos por meio de semelhante 'cultura' - que exclui tanto o autodidacta, herói marginal da cultura tradicional, como o homem culto, florão humanístico embalsamado e em vias de desaparecimento - é a 'reciclagem' cultural, reciclagem estética que constitui um dos elementos da 'personalização' generalizada do indivíduo, do encarecimento cultural em plena sociedade de concorrência e que equivale, guardadas todas as proporções, ao encarecimento do objecto por meio do condicionamento." (Baudrillard, 2010: 137)
}

A estética da sociedade de consumo relacionada por Baudrillard apresenta características presente na passagem do modernismo para o período pós-moderno: transformações culturais e econômico-mercadológicas que tendem a oferecer novos limites 
Contratos de comunicação e análise do discurso: bases teóricas aplicadas ao enunciado persuasivo de moda masculina

de Allan Koslakowski

e oportunidades de sempre estar se reeditando num tempo-espaço em constante alteração.

Podemos chamar de 'ciclos de padronização estética' e afirmar que são automatizados em escala comercial pelo sistema capitalista; tais ciclos fazem eclodir tendências e estilos planejados conforme a lógica dos produtos culturais, facilitando o que Prado (2008) afirma ser a construção de regimes de visibilidade e interação. Na busca de performance adequada, tanto na vida particular quanto profissionalmente, as relações admitidas e tematizadas pelos contratos tem se referido à busca pelos itens que traduzem o sucesso.

Neste contexto, a felicidade seria um momento em que o conflito entre as possibilidades pessoais e as exigências de ter sucesso na pós-modernidade tenderia a ser amenizado, pois realidades e exigências a se igualariam em determinado momento. Como uma área limite entre o ser (sujeito) e aquilo que ele considera ser o que esperam dele (alguém), a busca pela chamada evolução social insere o conflito da busca pela receita mais prática de auto-ajuste ao sistema capitalista-simbólico, conforme questiona Freire (2010: 53): “Como conciliar as aspirações de ser você mesmo e de ser alguém?".

O conflito descrito por Freire é resultado daquilo que se pode chamar de sintoma da sociedade civil evoluída, momento de passagem ao pós-moderno em que "se ampliara o hiato entre sentimento e ação" (FREIRE, 2010: 53). Afirmando a necessidade constante de autodefinição dos sujeitos, aqui se instala o problema: se o contrato de comunicação resulta de pacto entre enunciador e enunciatário, a sua continuidade tende a manter os ciclos de reciclagem descritos por Baudrillard e, portanto, são geradores de conflito e ao mesmo tempo atenuadores. As tematizações, a partir deste raciocínio, tendem a enunciar com mais sucesso ao continuar provocando a sensações do 'está por vir' (em ciclos de motivação para o sucesso).

Adaptar-se ao ambiente é a palavra de ordem recorrente nos variados setores da sociedade ocidental e promover a imagem de si mesmo como pessoa que está sempre à vontade por que busca estar sempre preparada parece ser um ponto de equilíbrio para o sujeito pós-moderno. No intervalo entre a autenticidade e a existência subjugada, como um estado de permanência diária sustentada pelos mercados, esta estratégia pós-modernista apontada por Fontenelle (2004) como um tipo de construção de cenários determinados para que os produtos de consumo possam ser comercializados, corrobora com a noção 
Contratos de comunicação e análise do discurso: bases teóricas aplicadas ao enunciado persuasivo de moda masculina

desenvolvida aqui sobre um quadro de referência 'da felicidade': o cenário é o sucesso na vida (em suas diferentes facetas).

Cabe ressaltar que, além das ações para a construção dos cenários de mercado, a sensação de realização pessoal insere na natureza interior dos sujeitos as condições de conduta social ditada pelos mercados; assim, produzem-se barreiras ou facilidades chamadas de 'ciclos motivacionais' reforçando a necessidade pelas receitas das publicações. Os esforços dos enunciadores da informação parecem apontar neste sentido: noticiar algo para vir a ser, tematizando os caminhos para a felicidade. Nesse contexto, uma resposta possível à pergunta de Freire estaria, pela ótica deste estudo, na manutenção dos hábitos pelo consumo dos discursos das mídias.

Podemos considerar então a necessidade das instâncias de comunicação visarem estratégias discursivas para os reciclos dos regimes de visibilidade pela edição de receitas de conduta. Esta construção das referências na atual dinâmica social buscará por novas formas de desconstrução e construção de experiências de felicidade possíveis. Em construindo pessoas cronicamente felizes, Freire (2010) organiza o que se convencionou chamar de capital psicológico positivo face a novos pareceres sobre a tangibilidade das experiências. Sintoma da pós-modernidade, a felicidade é considerada hoje, conforme o autor, um bem subjetivo e será trabalhado pelos mercados para impulsionar os ciclos de consumo, pois o capitalismo cultural, segundo Fontenelle (2010), plenamente desenvolvido parece em vias de promover as experiências vividas em valor negociável.

\section{CONCLUSÕES SOBRE O DISCURSO PERSUASIVO NO ANÚNCIO ARAMIS, MODA MASCULINA}

Em suas abordagens sobre as estratégias semióticas da publicidade, Lucia Santaella (2010) expôs os princípios da semiotização sociocultural, conceito que nos auxilia na compreensão daquilo que Rüdiger afirmou ser a orientação de conduta que os veículos de comunicação são capazes de realizar, em convergência ao contrato de comunicação que a realiza. Segundo a autora, os objetos têm suas funções e características enquanto definição técnica para o uso, para a finalidade industrial a qual pertencem mas, a partir do processo de semiotização esses objetos acabam recebendo significados que os projetam para além de 
Contratos de comunicação e análise do discurso: bases teóricas aplicadas ao enunciado persuasivo de moda masculina

seu valor de uso ou sua utilidade. É comum encontrar nos processos de planejamento de campanha os termos qualidade industrial e qualidade percebida, conceitos que os profissionais do marketing utilizam para posicionar produtos. Este posicionamento visa atingir propostas em que o objeto se transforme signo de si mesmo, caracterizando aquilo que Barthes (Santaella, 2010) afirma serem os aspectos da utilidade prática e os da marca sociocultural.

A esse respeito podemos dizer que valores são transferidos de uma qualidade para outra extrapolando a esfera do uso para configurar aquilo que poderia ser chamado de 'personalidade própria de produtos e serviços'. Dessa forma, a transferência de significados para a criação de um valor semiótico agregado trabalha com as crenças a respeito das necessidades constituídas pelo próprio trabalho da mídia, atribuindo às coisas capacidades de realizar ações culturalmente aceitas, tais como exclusividade, beleza, atualidade e felicidade, entre outras. Conforme afirma Santaella (2011: 132), "... frequentemente, tratase de transferir valores de pessoas, atrizes, estrelas da televisão e personalidades ilustres de todo tipo;" materializando as estratégias de marketing das empresas pensadas para os produtos. Além disso, concluímos ser exatamente esta a estética da sociedade de consumo, pois os regimes de visibilidade anteriormente relacionados enfatizam a necessidade por tais transferências de valor e colaboram para que o que podemos chamar perseguição da felicidade.

Os anúncios publicitários se utilizam do mesmo artifício inteligente, pois organizam seus discursos para que os potenciais consumidores se sintam mais próximos da felicidade. Com a mesma capacidade estética, o anúncio analisado - marca Aramis moda masculina, exibe um homem trajando costumes e saltando no mar, à margem da praia, em movimentação que cria a sensação de liberdade e uma relação de oposição. Veiculado na revista você s/a de setembro de 2011, apresenta a imagem estática de um homem pulando para fora d'água, como se emergisse triunfante do mar ou se estivesse dando continuidade à uma série e de movimentos, movimentando-se para frente e sentindo a água do mar. A imagem do anúncio é predominantemente calma, em maior parte azul, com o destaque "moda masculina", em inglês, aplicada no retângulo vermelho - que se alinha à esquerda do homem e vaza a página em sua margem direita. 
Contratos de comunicação e análise do discurso: bases teóricas aplicadas ao enunciado persuasivo de moda masculina

de Allan Koslakowski

A informação "SPRING / SUMMER COM MURILO ROSA" é grafada em branco sobre a imagem do céu, mantendo a sensação de leveza, pois alimenta a ordem da informação sobre o sentir-se bem exatamente nas condições de oposição que a relação roupa X local natural apresentam. A imagem estrutura-se pela continuidade dos movimentos, como se houvesse ali a brincadeira de vencer um obstáculo, mesmo que tenha ocorrido em momento anterior à sensação de liberdade caracterizada pela imagem. Esta oposição multiplica o sentido de liberdade daqueles que têm sucesso ao lembrar o sentido de tal movimento: é reconhecido culturalmente pela passagem de ano como bom presságio para o ano que inicia, ação em que as pessoas pulam sete ondas para um bom ingresso no 'Ano Novo'. O homem executivo está sem sapatos, o que provoca um segundo contra senso em vestir-se com o costume, acentuando a sensação de liberdade e o pertencimento ao grupo que pode desfrutar desta 'liberdade'.

A estratégia utilizada no anúncio para a transmissão das características e valorização das sensações foi a de enriquecer o produto da marca Aramis com os predicados reconhecidos associados ao sucesso do ator Murilo Rosa - modelo utilizado para a campanha, em meio à situação singular; a proposta criou não só a identificação do consumidor com tal sucesso como também possibilitou imaginar uma condição de liberdade e criatividade, elegância e pertencimento. $\mathrm{O}$ discurso deste anúncio propõe, a partir da simultaneidade entre a fruição da natureza e o uso do costume da marca Aramis em situação pouco provável - mesmo em cidades litorâneas brasileiras - a comemoração ou diversão que se pode alcançar, como um estado de espírito de quem utiliza os produtos da grife. O discurso do anúncio promove a identificação do executivo (que utiliza os produtos) com o sucesso (daquele que está representando o uso) e qualifica a sensação de felicidade e prosperidade na transferência de valores proporcionada pela idéia do sentir-se em meio ao natural com o uso da coleção primavera verão da marca Aramis. Neste sentido, concluímos, a roupa distancia-se da função de proteção e emerge como representante absoluto da autorrealização e status que desejam os enunciatários da revista Você S/A, assumindo valores relacionados ao sucesso.

Dessa maneira, a construção do discurso persuasivo proposto pela marca Aramis em relação ao uso do produto utiliza um enunciado imagético para significar um espaço entre a postura do Homem diante da natureza e o resultado da atuação daquele homem constituído 
Contratos de comunicação e análise do discurso: bases teóricas aplicadas ao enunciado persuasivo de moda masculina

de Allan Koslakowski

à moda Aramis. O ápice do sucesso do trabalho de um executivo - o ser alguém - é representado pelo maior grau de afastamento das condições de existência na Natureza, do silêncio contemplativo do mar, por exemplo, enquanto parte dela. Ouvimos sempre sobre a sensação universal dos seres humanos: o Homem vai à Natureza para alcançar seu silêncio (silêncio da urbanicidade, da terceiridade imposta pelo cotidiano das coisas do mundo, para o repouso da mente e para contemplar) e buscar um estado de espírito em que a primeiridade prevalece. O resultado do sucesso se encontra, assim, entre o cotidiano conquistado e a sensação de liberdade, pois o silêncio da natureza fala diretamente à percepção do ser livre, evocando a necessidade de um 'sentir-se bem ao voltar a ser parte da Natureza', crença que ganha realização na experiência de sucesso proposta pela marca.

\section{REFERÊNCIAS BIBLIOGRÁFICAS}

BAUDRILLARD, J. A sociedade de consumo. Lisboa: Edições 70, 2010.

CHARAUDEAU, P. Discurso das mídias. São Paulo: Contexto 2007.

DUARTE, R. Indústria cultural: uma introdução. Rio de Janeiro: FGV, 2010.

DURÃO, F. A.\& ZUIN, A.; (org) A indústria cultural hoje. São Paulo: Boitempo, 2008.

FILHO, J. F. (org) Ser feliz hoje. Rio de Janeiro: FGV, 2010.

FONTENELLE, I. A. Mídia, acesso e mercado da experiência. Revista Contra Campo, edição especial. Programa de Pós-Graduação em Comunicação. Rio de Janeiro, UFF, 2010.

HABERMAS, J. Verdade e justificação: ensaios filosóficos. São Paulo: Loyola, 2004. O discurso filosófico da modernidade. São Paulo: Martins Fontes, 2002.

JAMESON, F. A virada cultural. Rio de Janeiro: Civilização Brasileira, 2006. Pós-modernismo. São Paulo: Ática, 1996.

MAINGUENEAU, D. Pragmática para o discurso literário. São Paulo: Martins Fontes, 1996.

PEIRCE, C. S. Ilustrações da lógica da ciência. São Paulo: Ideias e Letras, 2008. Semiótica. (The collected papers of Charles Sanders Peirce) $3^{\mathrm{a} e d .}$ São Paulo: Perspectiva, 1999. 
Contratos de comunicação e análise do discurso: bases teóricas aplicadas ao enunciado persuasivo de moda masculina

de Allan Koslakowski

PRADO, J. L. A. Programas cognitivos e passionalização nos media e na publicidade. In Comunicação, mídia e consumo. Vol. 5, n.14. São Paulo: ESPM, 2008.

A invenção do mesmo e do outro na mídia semanal. DVD Hipermídia. São Paulo: PUC SP; CNPq, 2008.

RÜDIGER, Francisco. As teorias da comunicação. Porto Alegre: Penso, 2011.

SANTAELLA, L. Estratégias semióticas da publicidade. São Paulo: Cengage Learning, 2010. 
Contratos de comunicação e análise do discurso: bases teóricas aplicadas ao enunciado persuasivo de moda masculina

ANEXO

Imagem do anúncio.



Artigo submetido: 05/2012

Artigo aprovado: 06/2012 